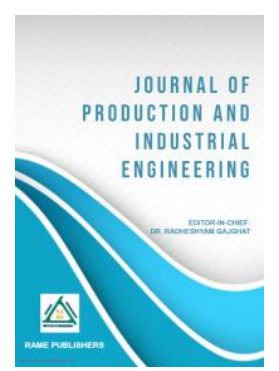

Sagar P. Kadu'

Assistant professor sagar.kadu1812@gmail.com

Pranaj Sambhaji Patil ${ }^{2}$

BE Student

pranajpatil01@gmail.com

\footnotetext{
${ }^{1,2}$ Department of Mechanical Engineering, JSPM Narhe Technical Campus, Pune, India
}

\title{
UAV (Unmanned Aerial Vehicle) for Agriculture Application- A State-of-the-Art Review
}

Abstract-Hard labour, a lot of effort, and man power were used in traditional agricultural methodology, causing a massive amount of worker force to be deployed over various places for different work like giving water, checking plants, seeding, spraying anti-infecting/ pesticides, putting fertilisers and calculating progress of plant and checking each and every plant for infection and insect attacks, and lots and lots of other time-consuming work. In this technologically advanced world, we can introduce some elements of technology that can make life easier for all farmers by providing them with a 24/7 working force and skilled labour in the form of various types of technological aspects, and thus what was previously capable of being done by humans can now be done with greater precision with the help of technology.

Keywords-UAV, Agriculture, drone, automation, advance applications.

\section{INTRODUCTION}

The man has reached the moon and are attempting to farm on Mars and space in the twenty-first century of modern technology and technological advancement. We may have reached the skies, but we have yet to reach the places that are within our grasp, one of which is today's agricultural sector. With the world's population expected to reach 9 billion by 2040, we are certainly lacking in modern agriculture in many ways. In order to feed the bellies of future generations, we must take all necessary precautions and measures now and on a global scale for more mature farming and providing all agricultural workers with a helping hand of technology [1]. Even in this technologically advanced era, $70 \%$ of farmers all over the world are using traditional methods of agriculture where hard labour is getting on their nerves and there is a large gap between demand and supply and

Review Article - Peer Reviewed

Published online - 31 December 2021

(C) 2021 RAME Publishers

This is an open access article under the CC BY 4.0 International License https://creativecommons.org/licenses/by/4.0/

Cite this article - Sagar P. Kadu, Pranaj Sambhaji Patil, "UAV (Unmanned Aerial Vehicle) for Agriculture Application- A State-of-theArt Review", Journal of Production and Industrial Engineering, RAME Publishers, vol. 2, issue 2, pp. 61-67, 2021.

https://doi.org/10.26706/ipie.2.2.20211206 not enough food to feed 7 billion and soon, we will be approaching 9 billion, so we need to take all of the globalization in technology [1]. Even in India, 85 percent of farmers are unfamiliar with terms like technology, and it is our responsibility to educate them about it so that we can focus our research on them and still make them adopt technology for their benefit, as it is their right to be a part of this technological revolution.

\section{WORKING PRINCIPLE}

A. Working principle of drone: (sprinkling pesticide):

A UAV (Unmanned Aerial Vehicle) is a flying machine that uses GPS coordinates and an autopilot to follow a pre-programmed course. Standard radio controls are also included, and the device can be piloted manually. The term "unmanned aerial vehicle" can refer to a variety of different types of aircraft, but is most commonly used for model planes and helicopters. The four propellers on a drone or quadcopter are fixed and oriented vertically [2]. Each propeller has its own speed control, allowing for full range of motion. The signals will be sent out by the transmitter, which will be received by the drone's receiver. The signal is sent from the receiver to the flight controller, where it will be processed. Accelerometer and gyroscope sensors were used to process the data. The 61 
signal will be processed and sent to the ESC, which will allow the motor to receive a preset amount of current based on the signal. The propellers, which rotate to generate thrust, are mechanically connected to the motors. The flight controller powers the FPV camera, which records video. Before being received by the ground receiver, the video signals will be processed by the transmitter. The pump pressurises the liquid in the storage tank, which then travels through the pipeline and into the nozzle, where it is sprayed, using Li-Po battery power.

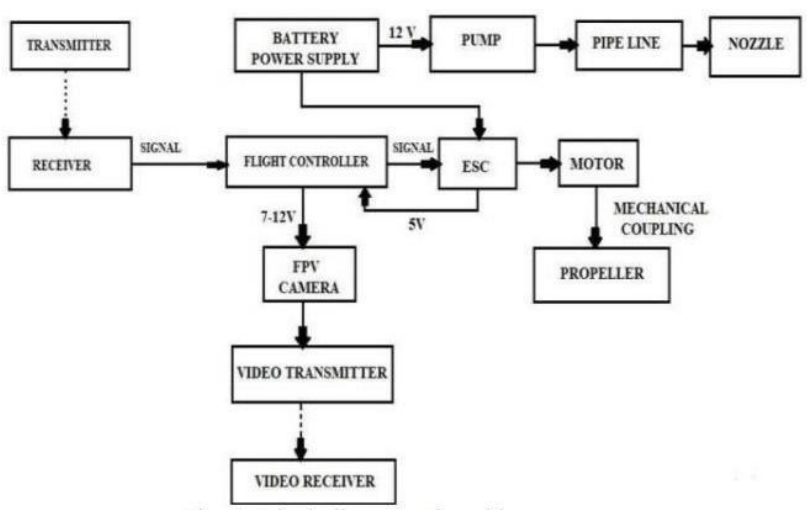

Fig.1 Process Block Diagram [2]

\section{CONCEPTUAL APPLICATIONS}

The concept of using drones as an agricultural accessory is fascinating and exciting in and of itself, but their application in various fields for various purposes is even more fascinating and awesome to work on. While farming involves many operations such as watering, inspecting plants, seeding, spraying antiinfecting/pesticides, applying fertiliser, calculating plant progress, and inspecting each and every plant for infection and insect attacks, there are many more [2].

- Real-Time Crop Monitoring: UAVs can provide ranchers with more precise images and recordings of their ranches if they have large terrains that are used for cultivating. These images are critical for monitoring the health and progress of the harvests.

- Nutrient and irrigation management: The use of drones has made field analysis much easier because the data captured by the drones allows them to identify areas with a scarcity of nutrients and water.
- Assessing Crop Stage: Ranchers can use flying pictures to survey the various stages of harvests, from planting to harvesting. With the harvests progressing, ranchers can make adequate plans for watering and pesticide application. Regardless, because of the simple access to this data, a rancher's reaction to any issues affecting their plants will be quick.
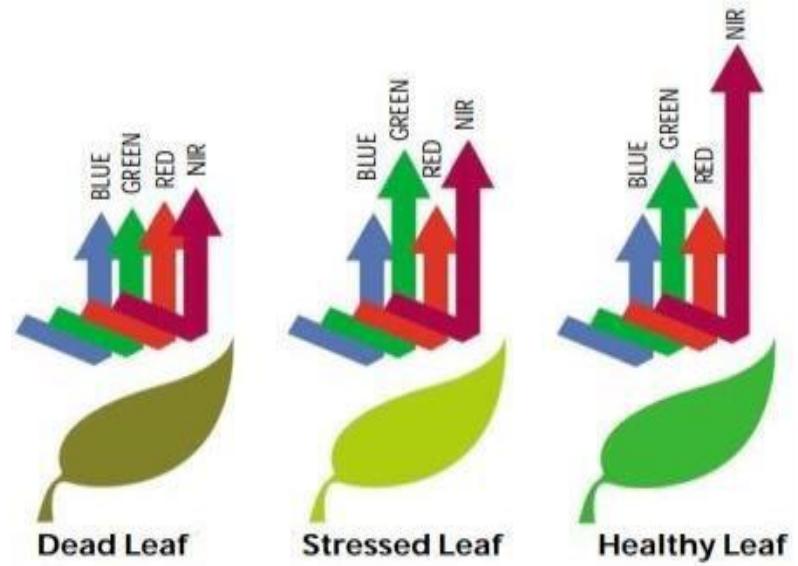

Fig. 2. Database of NDVI Definer Algorithms [3]

- Pesticide Sprinkling: Because there are many different types of crops, there are many different types of pesticide, and accumulating all of these in one device is difficult where some crops require liquid pesticide and others require solid pesticide or fertilizer that we can make it possible to use them as multipurpose, with different type of fittings [3]. Drone has a fitting that allows it to follow different mauves as planned or as driven and nozzle with different type of fitting to sprinkle different type of or different viscosity liquid with variation maintained by pump how much solution is to be sprinkled.

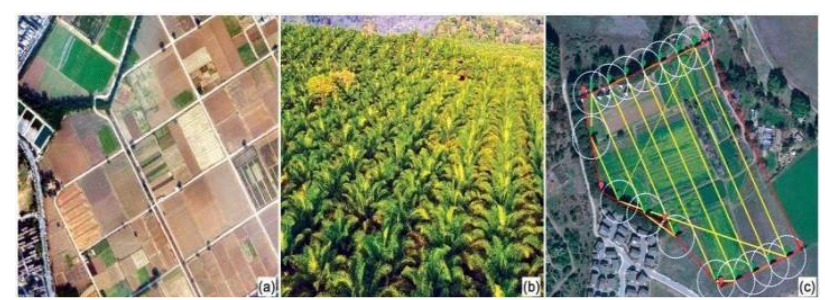

Fig. 3. Mapping the field and finding best route for the process [3]

\section{A. Necessity in automation}

When technology began to move in the direction of the future, we accepted it slowly and steadily, but we neglected the majority of our society while growing us as 
human self-centered develop technology for easing life in the urban zone and we kept a neglecting eye towards the ruler zone. However, no man or woman begins their life in a city. They begin in the ruler zone and work their way up the ladder; it may sound a little philosophical, but it is true. In the race of technology, our ruler sector has become increasingly disengaged from this technological upgrade, and as a wise man once said, "if not now, then when?" Basically, what is meant to say is that after realizing what we were missing, now is the time to work on it, not later. This technology, which we created for our own amusement, has the potential to become an important part of the agricultural sector. We never considered it, but it is already assisting a large number of farmers with harvesting and farming. As engineers, we are responsible for what we eat, which is grown by a farmer, in order to repay our debts in a unique way using technology. As a result, it is absolutely necessary.[4]

\section{B. Case Study}

1. Problem Statement: In the modern-day era of technological advancement, we as a country still use the majority conventional methodology of farming which costs more hard work, excess labour, superficial costing, and still no assurance of good quality product. To overcome this state of condition we can apply automation in the agricultural sector for the beneficial value for farmers. [4]

2. Structural Interface: Structural interface of model working.

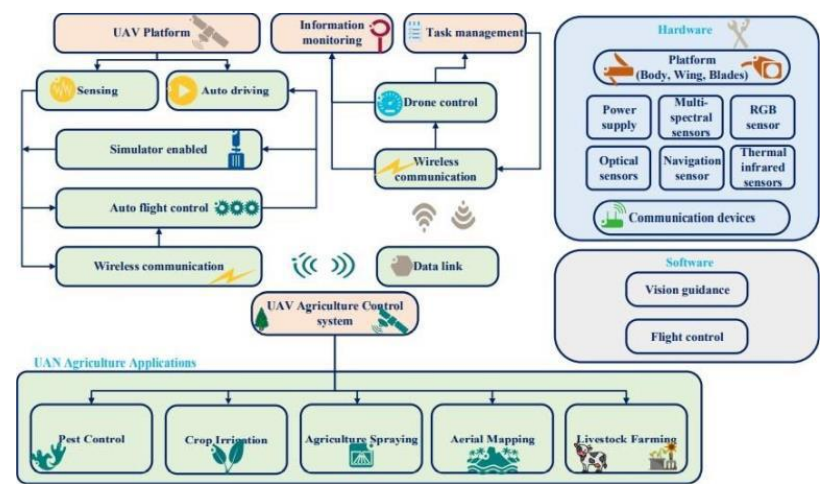

Figure 4. Structural Interface of Operation's [4]
3. Components and its Functions:

a. Quad copter frame: There is no such thing as a nonexclusive casing that is thought to be the best. However, various factors such as multi-rotor setup, pivoting second and adjusting, application, material, solidness, and segment mix influence each of the edges.

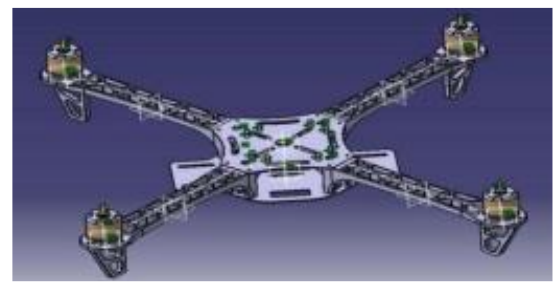

Figure 5. Skeleton Structure of Drone Frame [5]

b. ECS's: It is an abbreviation for Electronic Speed Controller, and it is used to control the motor controller's revolutions per minute (RPM). An electronic speed control, or ESC, is a circuit that controls the speed and direction of a servo-motor, as well as acting as a dynamic brake. [5]

c. Brushless Motors: Brushless DC electric motors are also known as electronically commutated motors (EC motors) or synchronous motors. They are fed by DC electricity through an inverter or switching power source, which generates an $\mathrm{AC}$ electric current to drive each phase of the motor using a closed loop controller.

d. Propeller: It is made of carbon fibre, which has a high strength-to-weight ratio. When the BLDC Rotate Propeller is mounted on it, lift fire is acted on it due to the shape of the propeller. [5]

e. The flight controller, an Arduino Uno microcontroller, aids in manoeuvring operations and also provides an Auto level function.

f. Battery and charger:The battery that can be used is a Li-Po battery with a capacity of $22000 \mathrm{mAh}$ and a voltage of 22.2 V. Six Li-Po cells are connected in series $(6 \times 3.7=22.2 \mathrm{~V})$ in this battery.

g. Connectors and controllers $(2.4 \mathrm{GHz})$ : The transmitter and receiver used are the Fly Sky CT6B 2.4Ghz $6 \mathrm{CH}$ and the FS-R6B. This combination has 
a range of approximately 1000 metres. This transmitter and receiver have a total of six channel options.

h. Camera: The camera that can be used is a $1200 \mathrm{TVL}$ HD FPV camera with a $2.8 \mathrm{~mm}$ lens, auto/color/black and white Day and night format.

i. A TS5828 32 $\mathrm{CH}$ mini transmitter can be connected to the camera to send video signals to a receiver on the ground.

j. Pump and Nozzle: A 12 V DC water pump with a 2.5 $\mathrm{L} / \mathrm{min}$ capacity can be used to pressurise the liquid. The pressurised liquid then enters the nozzle and sprays.

k. GPS: GPS Provide precise positioning, which aids in the progression of route finding and route determination for various operations.

\section{DRONE AGRICULTURE INDUSTRY}

Historically, adopting new technologies such as the Internet of Things (IoT), Big Data, and Artificial Intelligence has been one of the most effective ways that farmers have used or applied to meet and overcome the constant changes and challenges that accompany this sector and meet the growing food demands. The use of these technologies has resulted in the improvement of new and, in some cases, existing farming practises and tools that are already in use on farms. For example, one of the most popular new technologies currently being used in the farming sector to improve yields is the use of connected tractors. Drones are currently regarded as a relatively new, and even less mature, tool in comparison to the new technologies that are being used. Currently, there are two types of drones used in agriculture: medium-sized (which are primarily used for analysis purposes) and larger drones (which are used for planting and spraying of pesticides in the field) [6]. The first unmanned aerial systems (UAS) in agriculture were developed in the 1980s for crop dusting. Over the years, technological advancements in the agricultural sector have primarily been in the following areas: precise aerial application of pesticides and fertilisers over agricultural areas, and aerial imaging to support both crop field mapping and growth monitoring. The majority of agricultural UAS are Micro Air Vehicles (MAVs), which are fixed-wing or rotary-winged helicopters with low cost, low speed, low ceiling altitude, light weight, and a low payload weight with a short endurance period. Because the majority of farming applications only require low-to-medium endurance, the majority of UAS are gasoline or methanol-powered or electric-powered, and thus use rechargeable batteries or solar power. [7] It is important to note, however, that the advantages of UAS over existing technologies are based on their manoeuvrability, low operating costs, safety, and accuracy. With the development of the RemoteControlled Aerial Spraying System in 1983, Japan was the first country to attempt to use drones for aerial fertiliser application. It helped Japan's rice, soybean, and wheat crops increase yields by $20 \%$ because they were able to use drones effectively to control pests that could have affected overall production. Yamaha created the R50UAS helicopter in 1990, with a payload capacity of 44lb. Following that, in 1997, the R-MAX (unmanned helicopter) was developed, and by 2000, it had an azimuth and Differential Global Positioning System (DGPS) sensor system. Currently, 90 percent of crop protection in Japan is accomplished through the use of drones, which has facilitated pest control in the country. [8] The case of Japanese farms demonstrates that drones can be used effectively for pesticide spraying and fertiliser application on the majority of farms in African countries. The reason for this is that farm size per farmer in the two regions is comparable. The average farm size in Japan is 3.7 acres, while it is 2 acres in Africa. Aerial application of water, fertiliser, and pesticides has been shown to be extremely beneficial in farms.

\section{Advance ApPlicAtions Of Automation}

In addition to the drone for agriculture use we can always add some extra features or additives of some advanced technology where it will only increase the production and productivity. 
Some people might suggest the following:

- Robots are used for ground inspection and root level surveying.

- $\quad$ Rovers with a robot arm and NDVI Tech support can be used to check close-up data analysis, such as determining the number of plants by drone and justifying which tree or plant has what amount of vegetation by coordinating with the rover.

- Using rovers to supply root-to-root fertilizer.

- Rover can also be used to survey insect populations and vegetation growth.

- The Internet of Things (IOT) can be used to power the water supply system.

- IOT can be used to justify plant growth in terms of percent growth rate.

- Measuring soil properties and moisture can be accomplished using mechatronic components.

- All of the above systems can be applied and controlled by the centralizing IOT via a web page or application.

\section{IMPLEMENTATION OF ARTIFICIAL INTELLIGENCE IN}

\section{AGRICULTURE}

Agriculture contributes significantly to the economy. Agriculture automation is a major concern and a hot topic all over the world. The population is rapidly increasing, and with it, the demand for food and employment. The traditional methods used by farmers were insufficient to meet these requirements. As a result, new automated methods were developed. These new methods met food demands while also providing employment opportunities for billions of people. Agriculture has experienced a revolution as a result of artificial intelligence. This technology has protected crop yields from a variety of factors such as climate change, population growth, employment issues, and food security concerns [9-13].

The application of Artificial Intelligence (AI) in agriculture is expected to yield benefits such as cost savings in production, labour costs, and working hours, as well as a reduction in soil compaction. Agriculture's economic and environmental benefits, on the other hand, can only be realised if farmers are willing to use AI systems. In this study, the technology acceptance model (TAM) of Davis (1989) and the theory of planned behaviour (TPB) of Ajzen (1991) are used to see what behavioural factors influence $\mathrm{AI}$ acceptance in agriculture [14-16].

Agriculture automation is a major concern and emerging topic for all countries. The world's population is rapidly increasing, and as the population grows, so does the demand for food. Farmers' traditional methods are insufficient to meet rising demand, so they must wreak havoc on the soil by using harmful pesticides in greater quantities. This has a significant impact on agricultural practise, and as a result, the land remains barren and devoid of fertility. This paper discusses various automation practises such as Internet of Things, Wireless Communications, Machine Learning and Artificial Intelligence, and Deep Learning. Crop diseases, a lack of storage management, pesticide control, a lack of irrigation, and a lack of water management are some of the issues causing problems in the agricultural field, and all of these issues can be solved using the various techniques mentioned above [17-20].

\section{FUTURE SCOPE}

In the distant future, we can improve ourselves and this makes automation agriculture a habitual practise where 90 percent of the agricultural sector is under the wings of atomisation where the majority of people are getting their cultivation, irrigation, and harvesting done with various technologies and this will undoubtedly be a win for all. We can impose vertical farming in the inhabitant area where we as a human being cannot survive and that space of the mother earth is just being there as a waste and as we pick the grasp of tech we can sure say that such area can be used for vertical farming and indoor farming some companies are doing this on a commercial scale and lots and lots of people are doing research on a global level and we sure can see in the future we have achieved. 


\section{CONCLUSION}

Finally, now that we have adopted this technology as our own and use it on a daily basis, we need to extend our technological arms to the ruler side of our country, where our farmer brothers and sisters are still very much apart from it, and educate and provide them with technology for their daily hood of agriculture. Because we will soon reach 9 billion people and will need to feed them for many months, and the only people who can do that are farmers, and helping them now will eventually help us, and atomizing fields or sectors of agriculture will clearly solve many problems on many levels of society.

\section{REFERENCES}

[1] Kim, J.; Kim, S.; Ju, C.; Son, H.I. "Unmanned Aerial Vehicles in Agriculture: A Review of Perspective of Platform, Control, and Applications", IEEE Access 2019, 7, 105100-105115.

https://www.doi.org/10.1109/ACCESS.2019.2932119

[2] Karan Kumar Shaw, Vimalkumar R., "Design and Development of a Drone for Spraying Pesticides, Fertilizers and Disinfectants", International Journal of Engineering Research \& Technology (IJERT), Vol. 9 Issue 05, May-2020. http://dx.doi.org/10.17577/IJERTV9IS050787

[3] Shaik Himam Saheb \& Dr. G. Satish Babu, "Design and Analysis of LightWeight Agriculture Robot", Global Journal of Researches in Engineering: A Mechanical and Mechanics Engineering, Volume 17 Issue 6, 2017. https://engineeringresearch.org/index.php/GJRE/article/vie $\underline{\mathrm{w} / 1692}$

[4] N Deepa, Mohammad Zubair Khan, Prabadevi B, Durai Raj Vincent P M, Praveen Kumar Reddy Maddikunta, Thippa Reddy Gadekallu, "Multiclass Model for Agriculture development using Multivariate Statistical method", IEEE Access, Volume 4, 2016. https://doi.org/10.1109/ACCESS.2020.3028595

[5] S., R. Swarnkar, S. Bhukya and Namwade, G., "Application of Drone in Agriculture", Int. J. Curr. Microbiol. App. Sci., volume 8(01), 2019, pp 2500-2505. https://doi.org/10.20546/ijcmas.2019.801.264
[6] Donde R. et al. "Artificial Intelligence and Machine Learning in Rice Research", Applications of Bioinformatics in Rice Research. Springer, Singapore, pp pp 239-275, 2021. https://doi.org/10.1007/978-981-163997-5_12

[7] Vijay Rana and Mahima, "Impact of Drone Technology in Agriculture", Int. J. Curr. Microbiol. App. Sci., Volume 9(01), 2020, pp 1613-1619. https://doi.org/10.20546/ijcmas.2020.901.177

[8] Linlin Wang, Yubin Lan, Yali Zhang, Huihui Zhang, Muhammad Naveed Tahir, Shichao Ou, Xiaotao Liu, Pengchao Chen, "Applications and Prospects of Agricultural Unmanned Aerial Vehicle Obstacle Avoidance Technology in China", Sensors, Volume 19, 642, 2019. https://doi.org/10.3390/s19030642

[9] Giordan, D.; Adams, M.S.; Aicardi, I.; Alicandro, M.; Allasia, P.; Baldo, M.; De Berardinis, P.; Dominici, D.; Godone, D.; Hobbs, P.; "The use of unmanned aerial vehicles (UAVs) for engineering geology applications", Bull. Int. Assoc. Eng. Geol. 2020, volume 79, 3437-3481. https://doi.org/10.1007/s10064-020-01766-2

[10] Chirico, G.B.; Bonavolonta, F. "Metrology for Agriculture and Forestry 2019", Sensors, volume 20, 3498, 2020. https://doi.org/10.3390/s20123498

[11] Wang, L.; Lan, Y.; Zhang, Y.; Zhang, H.; Tahir, M.N.; Ou, S.; Liu, X.; Chen, P. "Applications and Prospects of Agricultural Unmanned Aerial Vehicle Obstacle Avoidance Technology in China", Sensors 2019, 19, 642. https://doi.org/10.3390/s19030642

[12] Al-Ghobari, H.M., Mohammad, F.S., "Intelligent irrigation performance: evaluation and quantifying its ability for conserving water in arid regions", Appl Water Sci,volume 1, 2011, pp 73-83. https://doi.org/10.1007/s13201-011$\underline{0017-y}$

[13] Wang, L.; Lan, Y.; Zhang, Y.; Zhang, H.; Tahir, M.N.; Ou, S.; Liu, X.; Chen, P. "Applications and Prospects of Agricultural Unmanned Aerial Vehicle Obstacle Avoidance Technology in China". Sensors 2019, 19, 642. https://doi.org/10.3390/s19030642

[14] Shiva Kumar, P. Srinivasa Pai, B. R. Shrinivasa Rao, "Radial-Basis-Function-Network-Based Prediction of Performance and Emission Characteristics in a Bio Diesel Engine Run on WCO Ester", Advances in Artificial Intelligence, vol. 2012, Article ID 610487, 7 pages, 2012. https://doi.org/10.1155/2012/610487 
[15] Imran Ali Lakhiar, Gao Jianmin, Tabinda Naz Syed, Farman Ali Chandio, Noman Ali Buttar, Waqar Ahmed Qureshi, "Monitoring and Control Systems in Agriculture Using Intelligent Sensor Techniques: A Review of the Aeroponic System", Journal of Sensors, vol. 2018, 18 pages, 2018. https://doi.org/10.1155/2018/8672769

[16] Shilin, W.; Jianli, S.; Xiongkui, H.; Le, S.; Xiaonan, W.C.W.; Zhichong, W.; Yun, L.; Changling, W. "Performances evaluation of four typical unmanned aerial vehicles used for pesticide application in China”, Int. J. Agric. Biol. Eng., 2017, 10, 22-31

[17] Dorte Schlesinger $€ 1,2$ and Simon J. Elsasser, "Revisiting sORFs: overcoming challenges to identify and characterize functional microproteins", The FEBS Journal, Volume 289, pp 53-74, 2021. https://doi.org/10.1111/febs.15769
[18] Richardson, A.; Signor, B.M.; Lidbury, B.A.; Badrick, T. "Clinical chemistry in higher dimensions:Machine-learning and enhanced prediction from routine clinical chemistry data", Clin. Biochem.2016,49, 1213-1220. https://doi.org/10.1016/j.clinbiochem.2016.07.013

[19] John V Stafford, "Implementing Precision Agriculture in the 21st Century", Journal of Agricultural Engineering Research, Volume 76(3), pp 267-275, July 2020. https://doi.org/10.1006/jaer.2000.0577

[20] Md. Wasim Aktar, Dwaipayan Sengupta, and Ashim Chowdhury, "Impact of pesticides use in agriculture: their benefits and hazards", Interdiscip Toxicol. 2009 Mar; Volume 2(1), pp 1-12. https://doi.org/10.2478/v10102-009-0001-7 